\title{
Antibacterial, Antioxidant Activity of Ethanolic Plant Extracts of Some Convolvulus Species and Their DART-ToF-MS Profiling
}

\author{
Asma'a Al-Rifai, ${ }^{1}$ Ahmad Aqel, ${ }^{2}$ Tarfah Al-Warhi, ${ }^{1}$ Saikh M. Wabaidur, \\ Zeid A. Al-Othman, ${ }^{2}$ and A. Yacine Badjah-Hadj-Ahmed ${ }^{2}$ \\ ${ }^{1}$ Department of Chemistry, College of Science, Princess Nourah bint Abdulrahman University, Riyadh, Saudi Arabia \\ ${ }^{2}$ Department of Chemistry, College of Science, King Saud University, Riyadh, Saudi Arabia \\ Correspondence should be addressed to Asma’a Al-Rifai; asma-alrifai@hotmail.com and Ahmad Aqel; aifseisi@ksu.edu.sa
}

Received 6 September 2017; Accepted 5 November 2017; Published 26 November 2017

Academic Editor: Gianni Sacchetti

Copyright (C) 2017 Asma’a Al-Rifai et al. This is an open access article distributed under the Creative Commons Attribution License, which permits unrestricted use, distribution, and reproduction in any medium, provided the original work is properly cited.

Convolvulus austroaegyptiacus Abdallah \& Sa'ad (CA) and Convolvulus pilosellifolius Desr. (CP) are commonly used in the Saudi Arabia folk medicine. They are potent in treating the ulcers and skin diseases. The lack of information about their biological activities led us to investigate the possible biological activities by determination of antibacterial and antioxidant activities of total ethanolic extracts and various fractions. Total flavonoid contents of the plants were determined by colorimetric method while total phenols were determined by using Folin-Ciocalteu method. In vitro antibacterial activity was studied against E. coli, P. aeruginosa, and B. subtilis, and the total antioxidant capacity was evaluated by radical scavenging method. $\mathrm{IC}_{50}$ were found to be $21.81,17.62$, and $3.31 \mu \mathrm{g} / \mathrm{mL}$ for $C A, C P$, and vitamin C, respectively, while the lowest $\mathrm{MIC}$ value of $0.25 \mathrm{mg} / \mathrm{mL}$ was recorded with $C P$ extract against B. subtilis. Around 21 compounds are tentatively elucidated from both plants using rapid, simple, and high-resolution analytical technique for chemical profiling of natural compounds by direct analysis in real-time of flight-mass spectrometry, of which 17 were not isolated or reported previously.

\section{Introduction}

Traditional medicine from plant extracts has proved to be clinically effective and relatively less toxic than the existing drugs [1]. Successful determination of biologically active compounds from plant material is largely dependent on the type of solvent used in the extraction procedure [2]. Many solvents have been used to extract active materials from plants such as alcohols (ethanol or methanol), diethyl ether, chloroform, ethyl acetate, $n$-butanol, and water [3].

Phytochemicals (secondary metabolites) are bioactive chemicals of plant origin. They are naturally synthesized in all parts of the plant body: bark, leaves, stems, roots, flowers, fruits, seeds, and so on [2]. They have been recognized as the basis for traditional herbal medicine practiced in the past and now [4]. All plant parts are usually screened for phytochemicals that may be present; the presence of a phytochemical of interest may lead to its further isolation, purification, and characterization. Then it can be used as the basis for a new pharmaceutical product.
Free radicals which are delivered as a consequence of typical biochemical responses in the body are involved in cancer, ischemic heart disease, inflammation, diabetes, aging, atherosclerosis, immunosuppression, and neurodegenerative disorders [5]. The human body has characteristic barrier system to counter free radical as proteins, for example, catalase, superoxide dismutase, and glutathione peroxidase. Selenium, vitamin $\mathrm{C}, \beta$-carotene, vitamin $\mathrm{E}$, lycopene, lutein, and different carotenoids have been utilized as supplementary antioxidants. Hence, the secondary metabolites of the plant as flavonoids and terpenoids act an important role in the defense against free radicals [6].

Recently, researchers have focused on increasing human infections caused by bacteria and fungi. Medicinal plants represent a rich source of antimicrobial agents. Because microorganisms have developed resistance to many antibiotics [7], the use of plant extracts and their isolated compounds as a resistant against microorganisms has been increased [8].

Antibacterial activity of different plant extracts was documented in the literature using various organic solvents such 


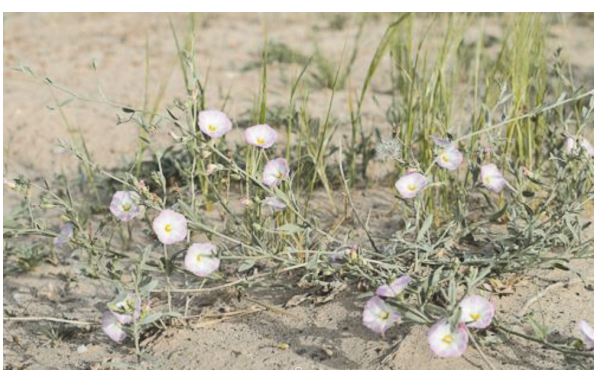

(a)

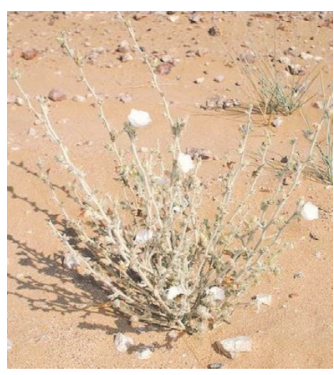

(b)

FIgUre 1: The two plants under investigation were (a) $C A$ and (b) $C P$ plants.

as ethanol, methanol, and petroleum ether. Muslim and his coauthor [9] studied the antibacterial activity of Convolvulus arvensis and the results demonstrated a promising effect. A significant cytotoxic activity for essential oil of Convolvulus althaeoides L. was reported [10]. Our search was carried out with the total extract (ethanol) and other solvent soluble fractions (diethyl ether, chloroform, ethyl acetate, and $n$-butanol) to found out the ability of traditional medicinal plants $C A$ and $\mathrm{CP}$ collected from Riyadh, KSA, as an antibacterial agents.

Convolvulaceae (bindweed family) is one of the largest plant families; it includes mostly twining herbs or shrubs, comprising about 85 genera and 2800 species that are further characterized by having the flowers solitary or in terminal [11]. Convolvulaceae family is well known and distinctive as a whole; however its division into species and genera might be difficult. In order to make the taxonomic relationship clear, seed morphology has been studied [12]. This family contains a large number of important plants which are used in treatment of various diseases such as headache, constipation, rheumatism, diabetes, and skin infection [13]. Members of this family mainly contain phenolics, tropane alkaloids, flavonoids, and coumarins [14].

Convolvulus is the largest genus of family Convolvulaceae; it contains 250 species present as herbs, trees, or shrubs [15]. Many Convolvulus species are valuable ornamentals, medicinal and food crops [16]. They possess cytotoxic [17], antioxidant, anti-inflammatory, antiasthma, antijaundice [18], anticancer, and antiulcer activities [19]. In addition, they can be used in treatment of coughs and asthma [13]. They contain many phytochemical groups such as phenolics, tropane alkaloids, sterols, resins, and sugars [14].

Convolvulus austroaegyptiacus Abdallah \& Saad (CA) and Convolvulus pilosellifolius Desr. (CP) are some of Convolvulus species. These plants are creeping or twining herbs or shrubs of various appearances and habits. Leaves are undivided or lobed, if parted mostly 1 of glabrous calyx, relatively big, not crowded, funnel-shaped, with entire, 5-angled or 5-plaited limb, and no regular colored stripes like those of Ipomoea [15]. These plants are mainly used in Saudi Arabia as folk medicine for treatment of ulcer diseases. Our research group studied the antiulcerogenic activity of $C A$ and the results showed a promising activity [20]. Although the antiulcerogenic activity of $C P$ is still under study, two compounds (quercetin and kaempferol) were characterized in its composition using HPLC [21].
Direct analysis in real-time of flight-mass spectrometry (DART) is a relatively recent ion source. Its atmospheric pressure ion source instantaneously ionizes any physical state samples (gases, liquids, or solids) in their native state under ambient conditions [22]. The power of DART ion source appears when it is combined with high-resolution mass analyzer as it gives exact molecular weight of ionized compounds from the samples and therefore provides matching molecular formula [23]. Recently, DART-ToF-MS is a strong candidate as a rapid and powerful technique for profiling of several types of samples including the major constituents of total plant species with high resolution mass number directly in real time. Many qualitative analyses of different organic compounds including phytochemicals, metabolites, pharmaceuticals, and synthetic organic molecules have been approved by DART-MS [24]. Since sample preparation or vacuum ionization steps can be omitted in DART-MS analysis, high throughput fingerprinting study of natural samples is possible and this feature is considered one of the most advantageous characteristics of DART ion source [23]. In addition to that, DART ion source ionizes moderately polar to highly nonpolar compounds [25]. Therefore, phenolic compounds are easily ionized and suitable for detection.

To our best knowledge, $C A$ and $C P$ plants are used in folk medicine for treatment of various diseases; however, they have never been studied as antioxidant and antibacterial. In addition, this is the first study using a unique DARTToF-MS for identification of chemical constituents of the two plants in which new compounds have been identified for the first time in these plants. Consequently, this work has been intended to explore the phytochemical screening and to assess the flavonoids content, total phenol, antimicrobial, antioxidant potentials and DART profiling of the total extracts and different fractions obtained from the aerial parts of $C A$ and $C P$. Figure 1 shows the plants under investigation.

\section{Materials and Methods}

2.1. General. Polyethylene glycol (PEG) with average relative molecular weight of 600 was purchased from Sigma-Aldrich, (Steinheim, Germany). All other solvents and chemicals used were purchased at analytical grade from Merck (Darmstadt, Germany). UV spectra were recorded on UV-1800 Shimadzu spectrophotometer (Tokyo, Japan) $\left(\lambda_{\max }\right.$ in $\mathrm{nm}$ ). 
2.2. Collection and Preparation of Samples. Aerial parts of $C A$ and $C P$ were collected during flowering stage from the Alrawda, Riyadh district, Saudi Arabia. Samples of the aerial parts were air dried in shade, reduced to fine powder, and kept for total phenols, flavonoids content, and phytochemical investigation.

2.3. Extraction and Fractionation Procedure. $100 \mathrm{~g}$ of air dried powder from each plant under investigation $(C A$ and $C P$ ) was separately extracted by refluxing in $200 \mathrm{~mL}$ ethanol $70 \%$ three times for 3 hours, filtered off, and concentered using rotary evaporator to obtain $50 \mathrm{~g}$ from each plants. The residue obtained from each plant was separately suspended in $200 \mathrm{~mL}$ water followed by filtering over a piece of cotton. The filtered aqueous layers were successively fractionated using several solvents such as diethyl ether, chloroform, ethyl acetate, and $n$-butanol, and the extracts were dried using anhydrous sodium sulfate, followed by concentrations to obtain $5,3,10$, and $30 \mathrm{~g}$ for diethyl ether, chloroform, ethyl acetate, and $n$ butanol, respectively, from $C A$ and 3, 2, 9 and $31 \mathrm{~g}$ for diethyl ether, chloroform, ethyl acetate, and $n$-butanol, respectively, from $C P$.

\subsection{Preliminary Phytochemical Screening. Preliminary phy-} tochemical screening was carried out for the ethanolic plant extracts and the four fractions from each plant (diethyl ether, chloroform, ethyl acetate, and n-butanol) for their usual plant secondary metabolites using the standard methods [26]. The screening was performed for coumarins, flavonoids, saponins, tannins, triterpenes/steroids, alkaloids, phenolic compounds, and anthraquinones. The precipitate formation or the color intensity was used as analytical responses to these tests.

2.5. Determination of Total Phenolic Compounds Contents. Total phenolic content in the plant ethanolic extract and fractions was determined using spectrophotometric method [27]. Briefly, $0.5 \mathrm{~mL}$ of Folin-Ciocalteu's reagent and $1 \mathrm{mg}$ from total extract and fractions was mixed separately with $10 \mathrm{~mL}$ of distilled water for $3 \mathrm{~min}$, followed by adding of $1 \mathrm{~mL}$ of saturated $\mathrm{Na}_{2} \mathrm{CO}_{3}$; then the volume was made up to $25 \mathrm{~mL}$. The samples were kept for $1 \mathrm{~h}$ in the dark place and the absorbance was measured at $750 \mathrm{~nm}$ wavelength against a blank. The samples were prepared in triplicate for each analysis and the mean value of absorbance was obtained. Different concentrations of gallic acid $(5,10,20,40,60,80$, 100 , and $150 \mathrm{mg} \mathrm{mL}^{-1}$ ) were prepared to obtain a calibration curve. The total phenolic content was expressed in milligrams of gallic acid equivalent per gram of extract [28].

2.6. Determination of Total Flavonoids Contents. Total flavonoids content was determined by a colorimetric method. $0.25 \mathrm{mg}$ from total extract and fractions was separately diluted with $5 \mathrm{~mL}$ of distilled water in a $10 \mathrm{~mL}$ measuring flask. Then $0.3 \mathrm{~mL}$ of a $5 \% \mathrm{NaNO}_{2}$ solution was added to the mixture. The test tubes were left in the dark for $6 \mathrm{~min}$, then $0.6 \mathrm{~mL}$ of a $10 \% \mathrm{AlCl}_{3} \cdot 6 \mathrm{H}_{2} \mathrm{O}$ solution was added, and the tubes were returned to the dark place for complete reaction. Consequently, $2 \mathrm{~mL}$ of $1 \mathrm{M} \mathrm{NaOH}$ was added to the mixture, and the total volume was made up to $10 \mathrm{~mL}$ with distilled water. After mixing of the solution, the absorbance was measured at $510 \mathrm{~nm}$ wavelength. The samples were prepared in triplicate for each analysis and the mean value of absorbance was obtained. The flavonoid content was calculated using a quercetin calibration curve and the results were expressed as $\mathrm{mg}$ of quercetin equivalent per gram of extract [29].

2.7. Evaluation of Antioxidant Activity. The antioxidant activity of the two plant crude extracts against 2,2-diphenyl-1picrylhydrazyl (DPPH) radical was determined by UV spectrophotometry at $518 \mathrm{~nm}$. The activity was measured according to the method previously described [30]. Different concentrations of the plant extracts were prepared using analytical methanol $\left(1,3,7,10,20,30,40,50,80\right.$, and $\left.100 \mu \mathrm{g} \mathrm{mL}^{-1}\right)$. Vitamin $\mathrm{C}$ was used as an antioxidant standard. $1 \mathrm{~mL}$ from each extract and $3 \mathrm{~mL}$ of methanol were mixed by $0.5 \mathrm{~mL}$ of $1.0 \mathrm{mM}$ DPPH in methanol and allowed to react at room temperature for 30 minutes. Same amount of methanol and DPPH was mixed to prepare the blank solution. The samples were prepared in triplicate for each analysis and the mean value of absorbance was obtained. The radical scavenging activity was calculated using the following formula:

$$
\% \text { inhibition }=\frac{A b-A a}{A b} \times 100
$$

in which $A b$ is absorption of the blank sample and $A a$ is absorption of the extract.

Extract concentration providing $50 \%$ inhibition $\left(\mathrm{IC}_{50}\right)$ was calculated from the plot of inhibition percentage against extract concentration.

2.8. Evaluation of Antibacterial Activity. The crude plant extracts and their successive fractions were subjected to antibacterial evaluation. Susceptibility of the bacterial strains to the two plant extracts and fractions was investigated using disk diffusion method [31]. The concentration of the cell suspension was adjusted to the 2.0 McFarland standard [30] and $50 \mu \mathrm{L}$ of each microorganism's suspension was spread on a Mueller-Hinton agar plate. Filter paper disks of $5 \mathrm{~mm}$ diameter impregnated with $5 \mathrm{mg}$ of each extract and fraction (50 $\mu \mathrm{L}$ of stock solutions) were placed onto the surface of the agar and incubated at $37^{\circ} \mathrm{C}$ for $24 \mathrm{~h}$. The antibacterial activity of the plant extracts and fractions was tested against three microorganisms, B. subtilis, P. aeruginosa, and E. coli. Doxycycline $\left(20 \mu \mathrm{g} \mathrm{mL}^{-1}\right)$ was used as positive control and ethanol solvent was used as negative control. The diameters of the inhibition zones were measured to the nearest millimeter.

\subsection{Determination of Minimum Inhibitory Concentration} (MIC). MIC represents the lowest extract concentration which prevents the microorganism visible growth. It was carried out for the bacterial strains to the ethanolic extracts of $C A$ and $C P$. A $100 \mu \mathrm{L}$ of the inoculum was spread onto $20 \mathrm{~mL}$ Mueller-Hinton broth (MHB) supplemented with the extracts at concentrations ranging from $\left(0.0-100 \mathrm{mg} \mathrm{mL}^{-1}\right)$ in Petri dishes, with 5\% dimethyl sulfoxide (DMSO). These serially cultures were then incubated at $37^{\circ} \mathrm{C}$ for $48 \mathrm{~h} .10 \%$ DMSO was used as a control [31]. 
TABLE 1: Phytochemical screening of ethanolic extract (total extract) and fractions from $C A$ and $C P$.

\begin{tabular}{|c|c|c|c|c|c|c|c|c|c|c|}
\hline \multirow{2}{*}{ Group } & \multicolumn{5}{|c|}{$C A$} & \multicolumn{5}{|c|}{$C P$} \\
\hline & Diethyl ether & $\mathrm{CHCl}_{3}$ & EtOAc & $n$-Butanol & Total extract & Diethyl ether & $\mathrm{CHCl}_{3}$ & EtOAc & $n$-Butanol & Total extract \\
\hline Alkaloids & - & - & - & - & - & - & - & - & - & - \\
\hline Flavonoids & - & - & \pm & + & + & - & - & \pm & + & + \\
\hline Saponins & - & - & + & + & + & - & - & + & + & + \\
\hline Steroids & + & + & - & - & + & + & + & - & - & + \\
\hline Tannins & - & - & - & + & + & - & - & - & + & + \\
\hline Triterpenoids & + & + & - & - & + & + & + & - & - & + \\
\hline Carbohydrate & - & - & \pm & + & + & - & - & \pm & + & + \\
\hline Amino acids \& proteins & - & - & + & + & + & - & - & + & + & + \\
\hline Anthraquinones & - & - & - & - & - & - & - & - & - & - \\
\hline Coumarins & - & - & + & + & + & - & - & + & + & + \\
\hline
\end{tabular}

+: present, - : absent, \pm : trace, $\mathrm{CHCl}_{3}$ : chloroform, and EtOAc: ethyl acetate.

2.10. DART-ToF-MS Conditions. High-resolution mass measurements were carried out using a Jeol the AccuTOF LC-plus JMS-T100 LP atmospheric pressure ionization ToF-MS (Jeol, Tokyo, Japan) equipped with a DART ion source (IonSense, Saugus, MA, USA). The mass spectrometer was operated in +ve-ion mode. The orifice 1 and 2 potentials were set to 20 and $5 \mathrm{~V}$. The ring lens potential was set to $13 \mathrm{~V}$. Orifice 1 was set to a temperature of $80^{\circ} \mathrm{C}$. The RF ion guide potential was $300 \mathrm{~V}$. The DART ion source was operated with $\mathrm{He}$ gas at $4.0 \mathrm{~L} \mathrm{~min}^{-1}$ flow. The gas heater was set to $200^{\circ} \mathrm{C}$. The potential on the discharge needle electrode of the DART source was set to $3.0 \mathrm{kV}$; perforated and grid electrode potentials were at 100 and $250 \mathrm{~V}$, respectively.

Data acquisition was monitored in the range of 10 to 1000 $\mathrm{m} / \mathrm{z}$ at acquisition rate 5 spectra $\mathrm{min}^{-1}$. The distance between the DART gun exit and mass spectrometer inlet was $10 \mathrm{~mm}$. In order to perform mass drift compensation for accurate mass measurements, a PEG with $200 \mu \mathrm{g} \mathrm{mL}^{-1}$ solution in methanol was applied before each analysis run. The elemental composition has been determined on selected peaks using the MassCentre software, version 1.3.m.

2.11. Statistical Analysis. All experiments were done in triplicate and the data were expressed as the mean \pm SD. $\mathrm{IC}_{50}$ values were determined by interpolation.

\section{Results and Discussion}

3.1. Phytochemical Screening. The two plant extracts were defatted with water followed by extracted with different organic solvents according to increasing the polarities; diethyl ether, chloroform, ethyl acetate, and n-butanol. Results obtained from qualitative analysis of phytochemicals of the total ethanolic extracts and their successive fractions of both plants under investigation $(C A$ and $C P$ ) are presented in Table 1.

Phytochemical analysis revealed the presence of coumarins, steroids, flavonoids, saponins, tannins, triterpenoids, carbohydrates, amino acids, and proteins, while both alkaloids and anthraquinones were absent in the crude extracts for both plants. Only steroids and triterpenoids were present in both diethyl ether and chloroform fractions. The chemical contents in the different fractions are considered as secondary metabolite components which are known to be biologically active ingredients. They are directly responsible for different activities such as antimicrobial, antioxidant, antifungal, and anticancer [32]. Normally these secondary metabolites components were isolated from the polar extract [33]. The most important bioactive compounds, which are flavonoids, were found in ethanol (total extract) and $n$-butanol fraction for both plants under investigation, while traces of flavonoids were present in ethyl acetate fraction. Many researchers reported that flavonoids and phenolic compounds in plants proved to possess multiple biological effects including antioxidant, anti-inflammatory, antimicrobial, antiangiogenic, anticancer, and antiallergic activities. In general, phenolic compounds and their derivatives are also considered as primary antioxidants or free radical scavengers [34].

3.2. Total Phenolic Compounds and Total Flavonoid Contents. The total phenolic contents of the ethanolic extract of $C A$ and $C P$ and their successive fractions were determined using the Folin-Ciocalteu reagent in comparison with standard gallic acid, and the result was expressed in terms of $\mathrm{mg}$ gallic acid $\mathrm{g}^{-1}$ extract. The results for both plants in Table 2 indicated that the total phenolic of the total extract (ethanolic extract) for $C A\left(125.44 \mathrm{mg} \mathrm{g}^{-1}\right)$ is lower than for CP $\left(129.97 \mathrm{mg} \mathrm{g}^{-1}\right)$. Total phenolic in ethyl acetate fraction of both plants (146.83 and $158.14 \mathrm{mg} \mathrm{g}^{-1}$ for $C A$ and $C P$, resp.) was higher than those which found with $n$-butanol fraction (92.00 and $95.05 \mathrm{mg} \mathrm{g}^{-1}$ for $C A$ and $C P$, resp.) followed by chloroform then diethyl ether fractions.

Colorimetric estimation of the total flavonoids of ethanolic extract of both plants and their successive fractions calculated based on quercetin proved that the total flavonoid contents of the total extract (ethanolic extract) for $C A$ $\left(91.61 \mathrm{mg} \mathrm{g}^{-1}\right)$ was lower than that of $C P\left(92.58 \mathrm{mg} \mathrm{g}^{-1}\right)$. The total flavonoids in ethyl acetate fraction of both plants (123.88 and $125.92 \mathrm{mg} \mathrm{g}^{-1}$ for $C A$ and $C P$, resp.) were higher than those of $n$-butanol fraction (45.40 and $46.37 \mathrm{mg} \mathrm{g}^{-1} C A$ and $C P$, resp.) followed by chloroform and diethyl ether fractions. 
TABLE 2: Total phenols (mg gallic acid/g extract) and total flavonoids (mg quercetin/g extract) of $C A$ and $C P$.

\begin{tabular}{|c|c|c|c|c|}
\hline \multirow{2}{*}{ Plant extract } & \multicolumn{2}{|c|}{$C A$} & \multicolumn{2}{|c|}{$C P$} \\
\hline & Total phenols & Total flavonoids & Total phenols & Total flavonoids \\
\hline Diethyl ether & $30.31 \pm 0.053$ & $9.15 \pm 0.026$ & $27.70 \pm 0.020$ & $8.14 \pm 0.026$ \\
\hline Chloroform & $39.00 \pm 0.182$ & $20.23 \pm 0.026$ & $45.09 \pm 0.061$ & $22.33 \pm 0.026$ \\
\hline Ethyl acetate & $146.83 \pm 0.089$ & $123.88 \pm 0.026$ & $158.14 \pm 0.078$ & $125.92 \pm 0.035$ \\
\hline n-Butanol & $92.00 \pm 0.178$ & $45.40 \pm 0.020$ & $95.05 \pm 0.046$ & $46.37 \pm 0.036$ \\
\hline Ethanolic extract & $125.44 \pm 0.044$ & $91.61 \pm 0.062$ & $129.97 \pm 0.087$ & $92.58 \pm 0.036$ \\
\hline
\end{tabular}

Values are mean $\pm \mathrm{SD}$ of 3 replicates.

TABLE 3: Percentage of inhibition of DPPH and $\mathrm{IC}_{50}$ for ethanolic extract of two plants at different concentrations $(\mu \mathrm{g} / \mathrm{mL})$ compared with vitamin C.

\begin{tabular}{lccc}
\hline $\begin{array}{l}\text { Concentration } \\
(\mu \mathrm{g} / \mathrm{mL})\end{array}$ & \multicolumn{2}{c}{ \% inhibition by plant } & $\begin{array}{c}\text { \% inhibition by } \\
\text { vitamin C }\end{array}$ \\
\hline 1 & $C A$ & $C P$ & $43.03 \pm 1.10$ \\
3 & $27.22 \pm 0.75$ & $31.84 \pm 1.07$ & $45.78 \pm 0.98$ \\
7 & $35.90 \pm 0.63$ & $39.56 \pm 1.10$ & $51.32 \pm 1.11$ \\
10 & $38.87 \pm 1.51$ & $41.09 \pm 0.92$ & $56.38 \pm 1.21$ \\
20 & $41.58 \pm 1.38$ & $43.18 \pm 1.26$ & $65.89 \pm 1.43$ \\
30 & $59.20 \pm 0.61$ & $60.37 \pm 1.58$ & $69.40 \pm 0.89$ \\
40 & $63.91 \pm 1.23$ & $64.58 \pm 1.42$ & $71.35 \pm 1.32$ \\
50 & $65.56 \pm 1.14$ & $66.21 \pm 0.85$ & $76.71 \pm 1.04$ \\
80 & $67.11 \pm 1.53$ & $69.67 \pm 1.45$ & $99.54 \pm 1.22$ \\
100 & $83.34 \pm 1.19$ & $87.48 \pm 1.12$ & 3.31 \\
$\mathrm{IC}_{50}(\mu \mathrm{g} / \mathrm{mL})$ & $86.11 \pm 1.15$ & $90.17 \pm 0.96$ & $100.96 \pm 1.06$ \\
\hline
\end{tabular}

Values are mean \pm SD of 3 replicates.

According to the total phenolic and total flavonoids assay, the obtained results proved that $C P$ extract has the highest total phenol and flavonoid contents. This demonstrated that the phenolic compounds of these plants might consist mainly of flavonoids, which are mainly in the form of glycosides, as they are more concentrated in the polar solvents, which is more effective in extracting phenolic compounds from plant materials than the less polar solvents [35]. Previous studies recorded that phenolic compounds including flavonoids are associated with strong antioxidant activity and they possess healthy benefits [36].

3.3. Antioxidant Activity. The antioxidant activity of ethanolic extract of $C A$ and $C P$ was measured by the ability to scavenge DPPH free radicals comparing with vitamin C. The scavenging effects of both plant extracts and the standard on the DPPH radical were expressed as half maximal inhibitory concentration $\left(\mathrm{IC}_{50}\right)$ values; the results are reported in Table 3. Lower $\mathrm{IC}_{50}$ value reflects higher DPPH radical scavenging activity. According to the results obtained, the ethanolic extract of $C P$ showed significant DPPH activity with the $\mathrm{IC}_{50}$ value of $17.62 \mu \mathrm{g} \mathrm{mL}^{-1}$, while $\mathrm{IC}_{50}$ of vitamin $\mathrm{C}$ as standard was $3.31 \mu \mathrm{g} \mathrm{mL}^{-1}$.

Different experiments have been performed to recognize the property of plant extracts to scavenge the free radicals
[37]. DPPH is a free radical compound which has scavenging ability for antioxidants samples and shows good absorbance at $517 \mathrm{~nm}$ [38]. Vitamin C is usually used as a standard antioxidant and it has a strong DPPH scavenging property [39]. Several studies demonstrated a linear correlation between antioxidant activity and phenolic content of plant extracts [40]. Our findings were not an exceptional case, as they indicated that $C P$ extract consists of high quantity of phenolic compounds and showed promising antioxidant activity with $17.62 \mu \mathrm{g} \mathrm{mL}^{-1} \mathrm{IC}_{50}$ value.

3.4. Antibacterial Activity. To our knowledge, no previous publications have reported the antibacterial activity of our plants. Therefore, antibacterial activity of total extract and successive fractions of $C A$ and $C P$ against the tested bacteria strains was assessed by the presence and absence of inhibition zones using disk diffusion method. The inhibition zone produced by the crude extracts and fractions for both plants on different bacterial strains was between $4 \mathrm{~mm}$ and $20 \mathrm{~mm}$. The antimicrobial studies revealed that the ethanolic extract and fractions of $C P$ showed inhibitory effects on $B$. subtilis, $P$. aeruginosa, and E. coli, while the crude extract and fractions of $C A$ exhibited less inhibitory effects on these microorganisms as shown in Table 4 . The MIC value was lowest for the ethanolic extract of $C P\left(0.25 \mathrm{mg} \mathrm{mL}^{-1}\right)$ against $B$. subtilis followed by the ethanolic extract of $C A$ $\left(0.78 \mathrm{mg} \mathrm{mL}^{-1}\right)$ against B. subtilis (Table 5).

Many previous studies revealed that the plants play an important role in development of new therapeutic sources. The first step in order to achieve this target is the in vitro antibacterial activity test [41]. Reviewing the literature, the presence of the secondary metabolites in the plant extract like saponins, tannins, flavonoids, coumarin, phenol, and triterpenoids has a promising activity against pathogens and helps the antibacterial activities of plants [42]. According to previous study, the ability of plant extracts against bacteria depends on the solubility of the bioactive constituents [43]. Our results clarified that the crude extract of $C P$ proved its efficiency to be used as source for antibacterial compounds compared with some standard antibiotics due to its inhibitory effects on B. subtilis, P. aeruginosa, and E. coli with lowest MIC value $\left(0.25 \mathrm{mg} \mathrm{mL}^{-1}\right)$ against $B$. subtilis.

3.5. DART-ToF-MS of the Plants Extract. Spectrometry analysis is one of the most powerful analytical methods available for exact structural identification of organic compounds. 
TABLE 4: Antibacterial activity of $C A$ and $C P$ extracts and fractions.

\begin{tabular}{|c|c|c|c|c|c|c|c|}
\hline \multirow{2}{*}{ Plant } & \multicolumn{5}{|c|}{ Inhibition zone (mm) } & \multirow{2}{*}{ Microorganisms tested } & \multirow{2}{*}{ Doxycycline (control) } \\
\hline & EtOH (crude) & Diethyl ether & $\mathrm{CHCl}_{3}$ & EtOAc & n-Butanol & & \\
\hline \multirow{3}{*}{$C A$} & 7 & 6 & 8 & 6.3 & 4 & B. subtilis & 13 \\
\hline & 16 & 11 & 12 & 10 & 4.3 & P. aeruginosa & 18 \\
\hline & 7 & 6.3 & 7 & 9 & 5 & E. coli & 10 \\
\hline \multirow{3}{*}{$C P$} & 9 & 6.2 & 10 & 8.2 & 5.7 & B. subtilis & 12 \\
\hline & 20 & 12.7 & 14 & 16.1 & 8.9 & P. aeruginosa & 20 \\
\hline & 9.8 & 6.5 & 8 & 10 & 7.7 & E. coli & 11 \\
\hline
\end{tabular}

IZ: inhibition zone, EtOH: ethanol, $\mathrm{CHCl}_{3}$ : chloroform, and EtOAc: ethyl acetate.

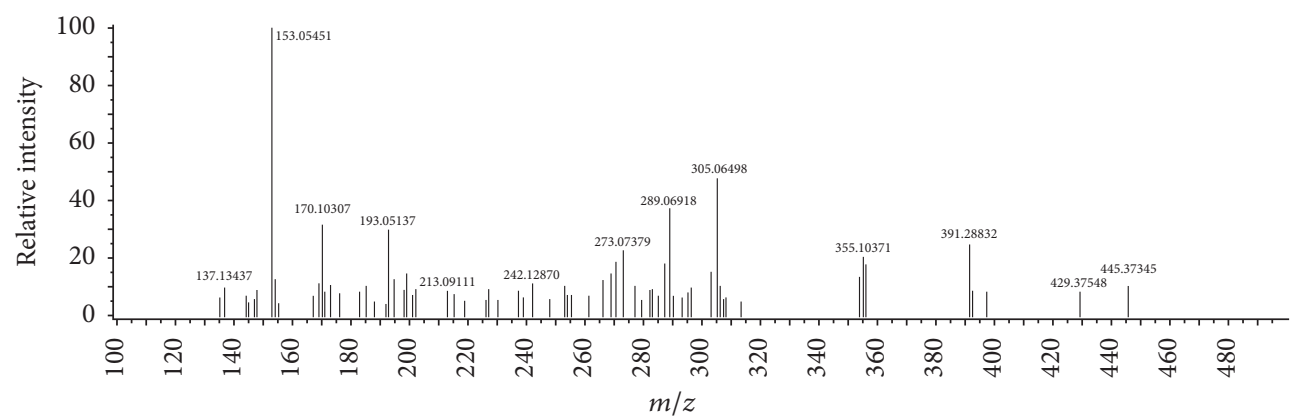

(a)

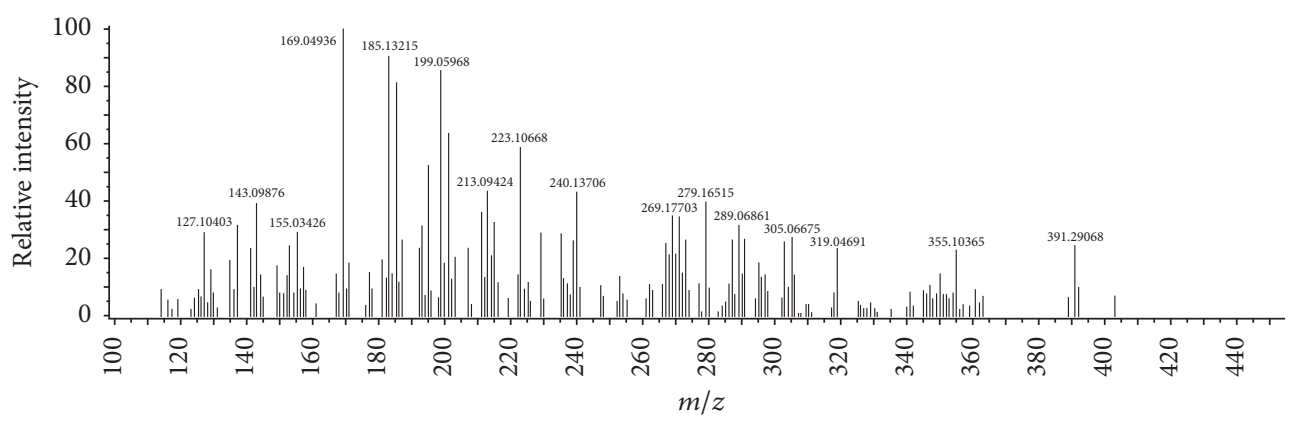

(b)

FIgURE 2: DART mass spectra of (a) $C A$ and (b) $C P$ plants.

TABLE 5: MIC against different strains of bacteria for ethanolic extracts of $C A$ and $C P$.

\begin{tabular}{lcc}
\hline Plant & MIC $(\mathrm{mg} / \mathrm{mL})$ & Bacterial strains \\
\hline \multirow{3}{*}{$C A$} & 0.78 & B. subtilis \\
& 1.54 & P. aeruginosa \\
& 1.20 & E. coli \\
\hline \multirow{3}{*}{$C P$} & 0.25 & B. subtilis \\
& 1.06 & P. aeruginosa \\
& 0.93 & E. coli \\
\hline
\end{tabular}

In this study, DART-ToF-MS profiles of the total $C A$ and $C P$ plants extract were obtained. Both plants were subjected to DART-ToF-MS analysis under the same conditions. As shown in Figure 2 and reported in Table 6, peaks corresponding to the molecular species of phellandrenes $(m / z 137)$, p-hydroxyphenylacetic acid $(m / z 153)$, scopoletin $(m / z 193)$, ferulic acid $(m / z$ 195), syringic acid $(m / z 199)$, pinosylvin $(m / z 213)$, apigenin/galangin $(m / z 271)$, naringenin $(m / z 273)$, kaempferol/luteolin/fisetin $(m / z 287)$, eriodictyol/aromadendrin $(m / z 289)$, quercetin $(m / z 303)$, taxifolin $(m / z 305)$, and scopolin $(m / z 355)$ were observed in the DART mass spectra in both plants. All selected peaks of the major components were on the type of protonated molecular ions $[\mathrm{M}+\mathrm{H}]^{+}$related to the highest peak intensity of the same compound. In addition, the unsaturated degree of each compound is reported in Table 6 .

Furthermore, three compounds, protocatechuic acid/ gentisic acid, vanillic acid, and myricetin corresponding to $m / z 155,169$, and 319 , respectively, have been observed in $C P$ plant but not detected in $C A$ plant.

Since its soft ionization technique, DART ion source provides relatively simple mass spectra with minimal fragmentations, consisting of the major constituents of the protonated molecules in the case of positive ion mode. All the 
TABLE 6: Exact mass data from the DART mass spectra of $C A$ and $C P$ plant constituents.

\begin{tabular}{|c|c|c|c|c|c|c|}
\hline Plant & $\begin{array}{c}\text { Experimental } \\
\text { mass }(m / z)\end{array}$ & $\begin{array}{l}\text { Calculated mass } \\
(\mathrm{m} / z)\end{array}$ & $\begin{array}{l}\text { Mass error } \\
(\mathrm{mmu})\end{array}$ & Formula & Remarks & $\begin{array}{c}\text { Unsaturation } \\
\text { degree }\end{array}$ \\
\hline \multirow{13}{*}{$C A$} & 137.13437 & 137.13303 & 1.34 & $\mathrm{C}_{10} \mathrm{H}_{17}$ & Phellandrenes & 2.5 \\
\hline & 153.05451 & 153.05516 & -0.65 & $\mathrm{C}_{8} \mathrm{H}_{9} \mathrm{O}_{3}$ & p-Hydroxyphenylacetic acid & 4.5 \\
\hline & 193.05137 & 193.05007 & 1.30 & $\mathrm{C}_{10} \mathrm{H}_{9} \mathrm{O}_{4}$ & Scopoletin & 6.5 \\
\hline & 195.06742 & 195.06572 & 1.70 & $\mathrm{C}_{10} \mathrm{H}_{11} \mathrm{O}_{4}$ & Ferulic acid & 5.5 \\
\hline & 199.05796 & 199.06063 & -2.67 & $\mathrm{C}_{9} \mathrm{H}_{11} \mathrm{O}_{5}$ & Syringic acid & 4.5 \\
\hline & 213.09111 & 213.09155 & -0.44 & $\mathrm{C}_{14} \mathrm{H}_{13} \mathrm{O}_{2}$ & Pinosylvin & 8.5 \\
\hline & 271.06318 & 271.06063 & 2.55 & $\mathrm{C}_{15} \mathrm{H}_{11} \mathrm{O}_{5}$ & Apigenin/galangin & 10.5 \\
\hline & 273.07379 & 273.07628 & -2.49 & $\mathrm{C}_{15} \mathrm{H}_{13} \mathrm{O}_{5}$ & Naringenin & 9.5 \\
\hline & 287.05627 & 287.05554 & 0.73 & $\mathrm{C}_{15} \mathrm{H}_{11} \mathrm{O}_{6}$ & Kaempferol/luteolin/fisetin & 10.5 \\
\hline & 289.06918 & 289.07119 & -2.01 & $\mathrm{C}_{15} \mathrm{H}_{13} \mathrm{O}_{6}$ & Eriodictyol/aromadendrin & 9.5 \\
\hline & 303.05202 & 303.05045 & 1.57 & $\mathrm{C}_{15} \mathrm{H}_{11} \mathrm{O}_{7}$ & Quercetin & 10.5 \\
\hline & 305.06498 & 305.06610 & -1.12 & $\mathrm{C}_{15} \mathrm{H}_{13} \mathrm{O}_{7}$ & Taxifolin & 9.5 \\
\hline & 355.10371 & 355.10287 & 0.84 & $\mathrm{C}_{16} \mathrm{H}_{19} \mathrm{O}_{9}$ & Scopolin & 7.5 \\
\hline \multirow{16}{*}{$C P$} & 137.13172 & 137.13303 & -1.31 & $\mathrm{C}_{10} \mathrm{H}_{17}$ & Phellandrenes & 2.5 \\
\hline & 153.05573 & 153.05516 & 0.57 & $\mathrm{C}_{8} \mathrm{H}_{9} \mathrm{O}_{3}$ & p-Hydroxyphenylacetic acid & 4.5 \\
\hline & 155.03426 & 155.03442 & -0.16 & $\mathrm{C}_{7} \mathrm{H}_{7} \mathrm{O}_{4}$ & $\begin{array}{c}\text { Protocatechuic acid/ } \\
\text { gentisic acid }\end{array}$ & 4.5 \\
\hline & 169.04936 & 169.05007 & -0.71 & $\mathrm{C}_{8} \mathrm{H}_{9} \mathrm{O}_{4}$ & Vanillic acid & 4.5 \\
\hline & 193.05084 & 193.05007 & 0.77 & $\mathrm{C}_{10} \mathrm{H}_{9} \mathrm{O}_{4}$ & Scopoletin & 6.5 \\
\hline & 195.06620 & 195.06572 & 0.48 & $\mathrm{C}_{10} \mathrm{H}_{11} \mathrm{O}_{4}$ & Ferulic acid & 5.5 \\
\hline & 199.05968 & 199.06063 & -0.95 & $\mathrm{C}_{9} \mathrm{H}_{11} \mathrm{O}_{5}$ & Syringic acid & 4.5 \\
\hline & 213.09424 & 213.09155 & 2.69 & $\mathrm{C}_{14} \mathrm{H}_{13} \mathrm{O}_{2}$ & Pinosylvin & 8.5 \\
\hline & 271.06165 & 271.06063 & 1.02 & $\mathrm{C}_{15} \mathrm{H}_{11} \mathrm{O}_{5}$ & Apigenin/galangin & 10.5 \\
\hline & 273.07482 & 273.07628 & -1.46 & $\mathrm{C}_{15} \mathrm{H}_{13} \mathrm{O}_{5}$ & Naringenin & 9.5 \\
\hline & 287.05517 & 287.05554 & -0.37 & $\mathrm{C}_{15} \mathrm{H}_{11} \mathrm{O}_{6}$ & Kaempferol/luteolin/fisetin & 10.5 \\
\hline & 289.06861 & 289.07119 & -2.58 & $\mathrm{C}_{15} \mathrm{H}_{13} \mathrm{O}_{6}$ & Eriodictyol/aromadendrin & 9.5 \\
\hline & 303.05172 & 303.05045 & 1.27 & $\mathrm{C}_{15} \mathrm{H}_{11} \mathrm{O}_{7}$ & Quercetin & 10.5 \\
\hline & 305.06675 & 305.06610 & 0.65 & $\mathrm{C}_{15} \mathrm{H}_{13} \mathrm{O}_{7}$ & Taxifolin & 9.5 \\
\hline & 319.04691 & 319.04536 & 1.55 & $\mathrm{C}_{15} \mathrm{H}_{11} \mathrm{O}_{8}$ & Myricetin & 11 \\
\hline & 355.10365 & 355.10287 & 0.78 & $\mathrm{C}_{16} \mathrm{H}_{19} \mathrm{O}_{9}$ & Scopolin & 7.5 \\
\hline
\end{tabular}

results prove that DART-ToF-MS is an appropriate method to differentiate between the two studied plants and for rapid identification of their major components, which mainly consist of flavonoids and phenols as mentioned in the phytochemical screening section.

On the other hand, the unsaturated degree of each compound helps to predict the chemical structures by determination how many double bond and rings are present in the compound, which also confirms the expected flavonoids and phenols compounds. It should be noted that some compounds such as apigenin and galangin have the same molecular formula and exact mass. Therefore, they cannot be distinguished on the basis of high-resolution mass spectrometry using DART-ToF-MS technique.

\section{Conclusion}

We demonstrate that DART-ToF-MS combined by multivariate analysis allows for rapid screening and metabolic characterization of different compounds from plant extracts without complex metabolic preparation steps such as phenol and flavonoid compounds. With this method, 21 phenol and flavonoid compounds are tentatively detected and identified in $C A$ and $C P ; 17$ of them are reported from these plants for the first time. The obtained results confirmed that DART-ToF-MS data were specific and valuable since it can directly ionize various organic molecules. Therefore, it would be a technique of choice for simple and rapid screening of natural products and a wide variety of materials with very simple or no sample preparation. The newly discovered phenol and flavonoid compounds expand our understanding on the chemical constituents of $C A$ and $C P$ and can be targets for further phytochemical studies. The literature survey indicated that there is no research that has been carried out on antioxidant potent and antibacterial activity of these plant species; therefore, this study can be a guideline for further biological activities investigations. 


\section{Conflicts of Interest}

The authors declare no conflicts of interest.

\section{Acknowledgments}

This work was funded by the Deanship of Scientific Research at Princess Nourah bint Abdulrahman University, through the Research Groups Program Grant no. RGP-1438-0007.

\section{References}

[1] A. S. Awaad, R. M. El-Meligy, S. A. Qenawy, A. H. Atta, and G. A. Soliman, "Anti-inflammatory, antinociceptive and antipyretic effects of some desert plants," Journal of Saudi Chemical Society, vol. 15, no. 4, pp. 367-373, 2011.

[2] T. P. Lalitha and P. Jayanthi, "Preliminary studies on phytochemicals and antimicrobial activity of solvent extracts of Eichhornia crassipes (Mart.) Solms," Asian Journal of Plant Science \& Research, vol. 2, pp. 115-122, 2012.

[3] H. Poulson and S. Preime Loft, "Role of oxidative DNA damage in cancer initiation and promotion," European Journal of Cancer Preventive, vol. 7, pp. 9-16, 1998.

[4] R. Govindarajan, M. Vijayakumar, and P. Pushpangadan, "Antioxidant approach to disease management and the role of "Rasayana" herbs of Ayurveda," Journal of Ethnopharmacology, vol. 99, no. 2, pp. 165-178, 2005.

[5] S. Chanda, M. Kaneria, and R. Nair, "Antibacterial activity of Psoralea corylifolia L. seed and aerial parts with various extraction methods," Research Journal of Microbiology, vol. 6, no. 2, pp. 124-131, 2011.

[6] G. O. Adeshina, J. A. Onaolapo, J. O. Ehinmidu, and L. E. Odama, "Phytochemical and antimicrobial studies of the ethyl acetate extract of Alchornea cordifolia leaf found in Abuja, Nigeria," Journal of Medicinal Plants Research, vol. 4, no. 8, pp. 649-658, 2010.

[7] R. Muslim, R. Fozia, Ali et al., "Comparative antibacterial study of Convolvulus arvensis collected from different areas of Khyber Pakhtunkhwa, Pakistan," IRJP, vol. 3, pp. 220-222, 2012.

[8] M. Hassine, A. Zardi-Berguaoui, M. Znati, G. Flamini, H. Ben Jannet, and M. A. Hamza, "Chemical composition, antibacterial and cytotoxic activities of the essential oil from the flowers of Tunisian Convolvulus althaeoides L.," Natural Product Research (Formerly Natural Product Letters), vol. 28, no. 11, pp. 769-775, 2014.

[9] K. R. Robertson, "Odonellia, a New Genus of Convolvulaceae from Tropical America," Brittonia, vol. 34, no. 4, p. 417, 1982.

[10] K. N. Abdel Khalik and A. K. Osman, "Seed morphology of some species of Convolvulaceae from Egypt (Identification of species and systematic significance)," Feddes Repertorium, vol. 118, no. 1-2, pp. 24-37, 2007.

[11] A. M. Donia, S. I. Alqasoumi, A. S. Awaad, and L. Cracker, "Antioxidant activity of Convolvulus hystrix Vahl and its chemical constituents," Pakistan Journal of Pharmaceutical Sciences, vol. 24, pp. 143-147, 2011.

[12] S. Nacef, H. B. Jannet, P. Abreu, and Z. Mighri, "Phenolic constituents of Convolvulus dorycnium L. flowers," Phytochemistry Letters, vol. 3, no. 2, pp. 66-69, 2010.

[13] A. M. Migahid, Flora of Saudi Arabia, KSA. University Libraries, King Saud University, Riyadh, 3rd edition, 1988.
[14] S. Stefanović, L. Krueger, and R. G. Olmstead, "Monophyly of the convolvulaceae and circumscription of their major lineages based on DNA sequences of multiple chloroplast loci," American Journal of Botany, vol. 89, no. 9, pp. 1510-1522, 2002.

[15] M. Arora and M. Malhotra, "A review on macroscopical, phytochemical and biological studies on Convolvulus arvensis (field bindweed," Pharmacologyonline, vol. 3, p. 1296, 2011.

[16] W. J. Griffin and G. D. Lin, "Chemotaxonomy and geographical distribution of tropane alkaloids," Phytochemistry, vol. 53, no. 6, pp. 623-637, 2000.

[17] F. G. Todd, F. R. Stermitz, P. Schultheis, A. P. Knight, and J. Traub-Dargatz, "Tropane alkaloids and toxicity of Convolvulus arvensis," Phytochemistry, vol. 39, no. 2, pp. 301-303, 1995.

[18] A. S. Awaad, A. A. Al-Rifai, R. M. El-Meligy, A. M. Alafeefy, and M. E. Zain, "New Activities for Isolated Compounds from Convolvulus austro-aegyptiacus as Anti-ulcerogenic, Anti-Helicobacter pylori and Their Mimic Synthesis Using Bio-guided Fractionation," Phytotherapy Research, vol. 29, no. 9, pp. 13111316, 2015.

[19] A. Al-Rifai, A. Aqel, A. Awaad, and Z. A. ALOthman, "Analysis of Quercetin and Kaempferol in an Alcoholic Extract of Convolvulus pilosellifolius using HPLC," Communications in Soil Science and Plant Analysis, vol. 46, no. 11, pp. 1411-1418, 2015.

[20] V. Bajpai, D. Sharma, B. Kumar, and K. P. Madhusudanan, "Profiling of Piper betle Linn. Cultivars by direct analysis in real time mass spectrometric technique," Biomedical Chromatography, vol. 24, no. 12, pp. 1283-1286, 2010.

[21] S. Banerjee, K. P. Madhusudanan, S. P. S. Khanuja, and S. K. Chattopadhyay, "Analysis of cell cultures of Taxus wallichiana using direct analysis in real-time mass spectrometric technique," Biomedical Chromatography, vol. 22, no. 3, pp. 250-253, 2008.

[22] A. Singh, V. Bajpai, M. Srivastava, K. R. Arya, and B. Kumar, "Rapid screening and distribution of bioactive compounds in different parts of Berberis petiolaris using direct analysis in real time mass spectrometry," Journal of Pharmaceutical Analysis, vol. 5, no. 5, pp. 332-335, 2015.

[23] M. A. Hossain and M. R. Nagooru, "Biochemical profiling and total flavonoids contents of leaves crude extract of endemic medicinal plant Corydyline terminalis L. Kunth," Pharmacognosy Journal, vol. 3, no. 24, pp. 25-30, 2011.

[24] G. Morlock and Y. Ueda, "New coupling of planar chromatography with direct analysis in real time mass spectrometry," Journal of Chromatography A, vol. 1143, no. 1-2, pp. 243-251, 2007.

[25] M. A. Hossain, M. D. Shah, C. Gnanaraj, and M. Iqbal, "In vitro total phenolics, flavonoids contents and antioxidant activity of essential oil, various organic extracts from the leaves of tropical medicinal plant Tetrastigma from Sabah," Asian Pacific Journal of Tropical Medicine, vol. 4, no. 9, pp. 717-721, 2011.

[26] J. Bao, Y. Cai, M. Sun, G. Wang, and H. Corke, "Anthocyanins, flavonols, and free radical scavenging activity of Chinese bayberry (Myrica rubra) extracts and their color properties and stability," Journal of Agricultural and Food Chemistry, vol. 53, no. 6, pp. 2327-2332, 2005.

[27] M. Liu, X. Q. Li, C. Weber, C. Y. Lee, J. Brown, and R. H. Liu, "Antioxidant and antiproliferative activities of raspberries," Journal of Agricultural and Food Chemistry, vol. 50, no. 10, pp. 2926-2930, 2002.

[28] G. A. Ayoola, T. Sofidiya, O. Odukoya, and H. A. B. Coker, "Phytochemical screening and free radical scavenging activity of some Nigerian medicinal plants," Journal of Pharmaceutical Sciences and Pharmacy Practice, vol. 8, pp. 133-136, 2006. 
[29] N. Thitilertdecha, A. Teerawutgulrag, and N. Rakariyatham, "Antioxidant and antibacterial activities of Nephelium lappaceum L. extracts," LWT - Food Science and Technology, vol. 41, no. 10, pp. 2029-2035, 2008.

[30] Testing, Sixteenth informational supplement M100-S16, Clinical and Laboratory Standards Institute, Clinical and Laboratory Standards Institute, Performance Standards for Antimicrobial Susceptibility, Wayne, 2006.

[31] M. Khadidja, B. Nassima, B. Chahrazed, and F. Xavier, "Chemical composition and antimicrobial activity of essential oils isolated from Algerian Juniperus phoenicea L. and Cupressus sempervirens L," Journal of Medicinal Plants Research, vol. 4, pp. 959-964, 2010.

[32] G. N. Anyasor, K. Olusola Ogunwenmo, O. A. Oyelana, and B. E. Akpofunure, "Phytochemical constituents and antioxidant activities of aqueous and methanol stem extracts of Costus afer Ker Gawl. (Costaceae)," African Journal of Biotechnology, vol. 9, no. 31, pp. 4880-4884, 2010.

[33] G. Hatipoĝlu, M. Sökmen, E. Bektaş et al., "Automated and standard extraction of antioxidant phenolic compounds of Hyssopus officinalis L. ssp. angustifolius," Industrial Crops and Products, vol. 43, no. 1, pp. 427-433, 2013.

[34] J. Liu, C. Wang, Z. Wang, C. Zhang, S. Lu, and J. Liu, “The antioxidant and free-radical scavenging activities of extract and fractions from corn silk (Zea mays L.) and related flavone glycosides," Food Chemistry, vol. 126, no. 1, pp. 261-269, 2011.

[35] C. Pattanaik, C. S. Reddy, and N. K. Dhal, "Phytomedicinal study of coastal sand dune species of Orissa," Indian Journal of Traditional Knowledge, vol. 7, no. 2, pp. 263-268, 2008.

[36] S. Sakanaka, Y. Tachibana, and Y. Okada, "Preparation and antioxidant properties of extracts of Japanese persimmon leaf tea (Kakinoha-cha)," Food Chemistry, vol. 89, no. 4, pp. 569-575, 2005.

[37] K. Pavithra and S. Vadivukkarasi, "Evaluation of free radical scavenging activity of various extracts of leaves from Kedrostis foetidissima (Jacq.) Cogn," Food Science and Human Wellness, vol. 4, no. 1, pp. 42-46, 2015.

[38] M.-Y. Juan and C.-C. Chou, "Enhancement of antioxidant activity, total phenolic and flavonoid content of black soybeans by solid state fermentation with Bacillus subtilis BCRC 14715," Food Microbiology, vol. 27, no. 5, pp. 586-591, 2010.

[39] L. Tona, K. Kambu, N. Ngimbi, K. Cimanga, and A. J. Vlietinck, "Antiamoebic and phytochemical screening of some Congolese medicinal plants," Journal of Ethnopharmacology, vol. 61, no. 1, pp. 57-65, 1998.

[40] F. Pensec, A. Szakiel, C. Pączkowski et al., "Characterization of triterpenoid profiles and triterpene synthase expression in the leaves of eight Vitis vinifera cultivars grown in the Upper Rhine Valley," Journal of Plant Research, vol. 129, no. 3, pp. 499-512, 2016.

[41] E. G. Nenaah and M. E. Ahmed, "Antimicrobial activity of extracts and latex of calotropis procera (Ait.) and synergistic effect with reference antimicrobials," Research Journal of Medicinal Plant, vol. 5, no. 6, pp. 706-716, 2011.

[42] F. A. Khan, I. Hussain, S. Farooq, M. Ahmad, M. Arif, and I. Ur Rehman, "Phytochemical Screening of Some Pakistanian Medicinal Plants," Middle-East Journal of Scientific Research, vol. 8, pp. 575-578, 2011.

[43] A. Waterhouse, "Determination of total phenolics," Current Protocols in Food Analytical Chemistry, pp. I1.1.1-I1.1.8, 2003. 


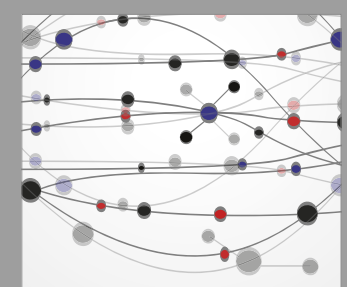

The Scientific World Journal
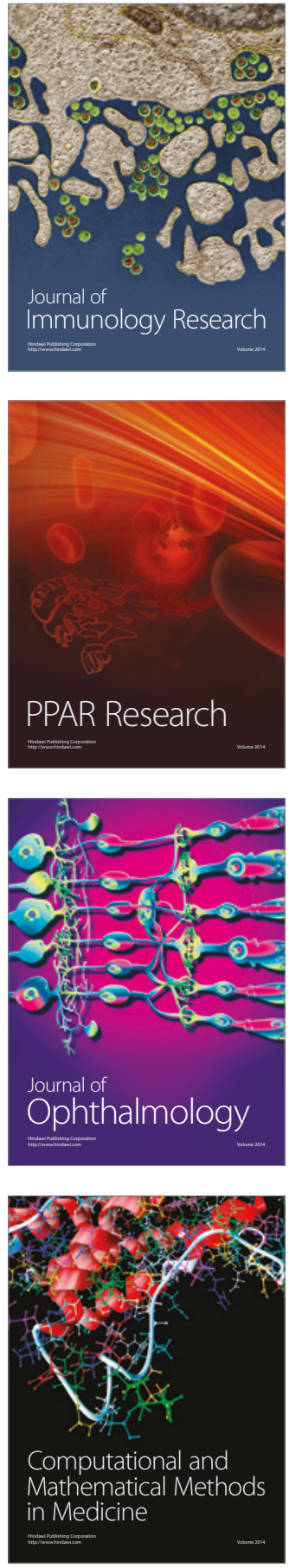

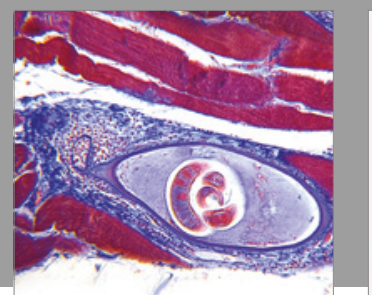

Gastroenterology Research and Practice
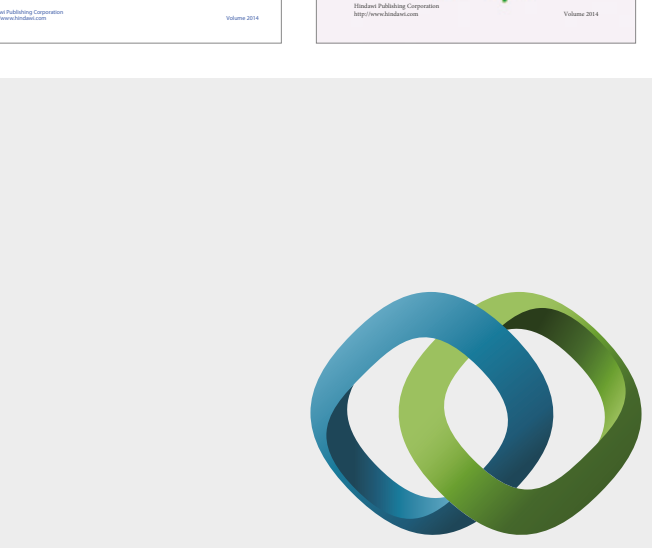

\section{Hindawi}

Submit your manuscripts at

https://www.hindawi.com
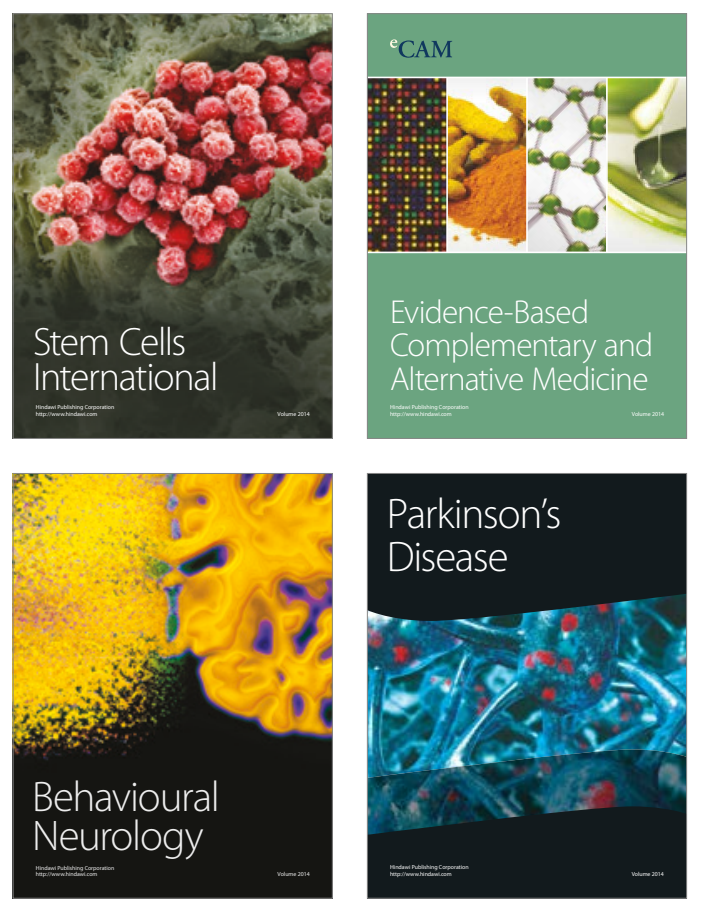
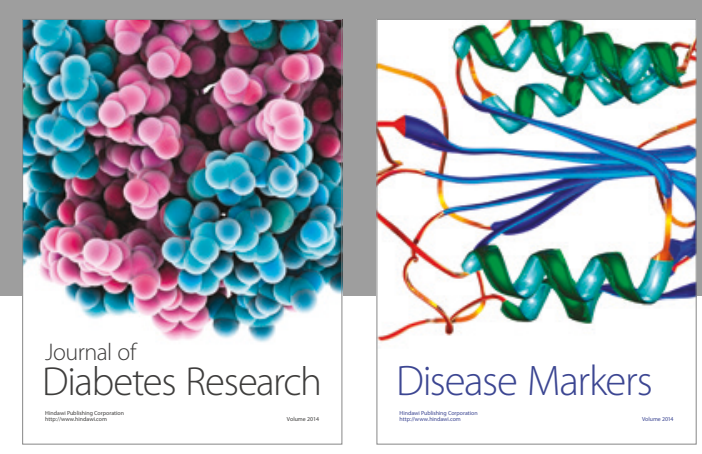

Disease Markers
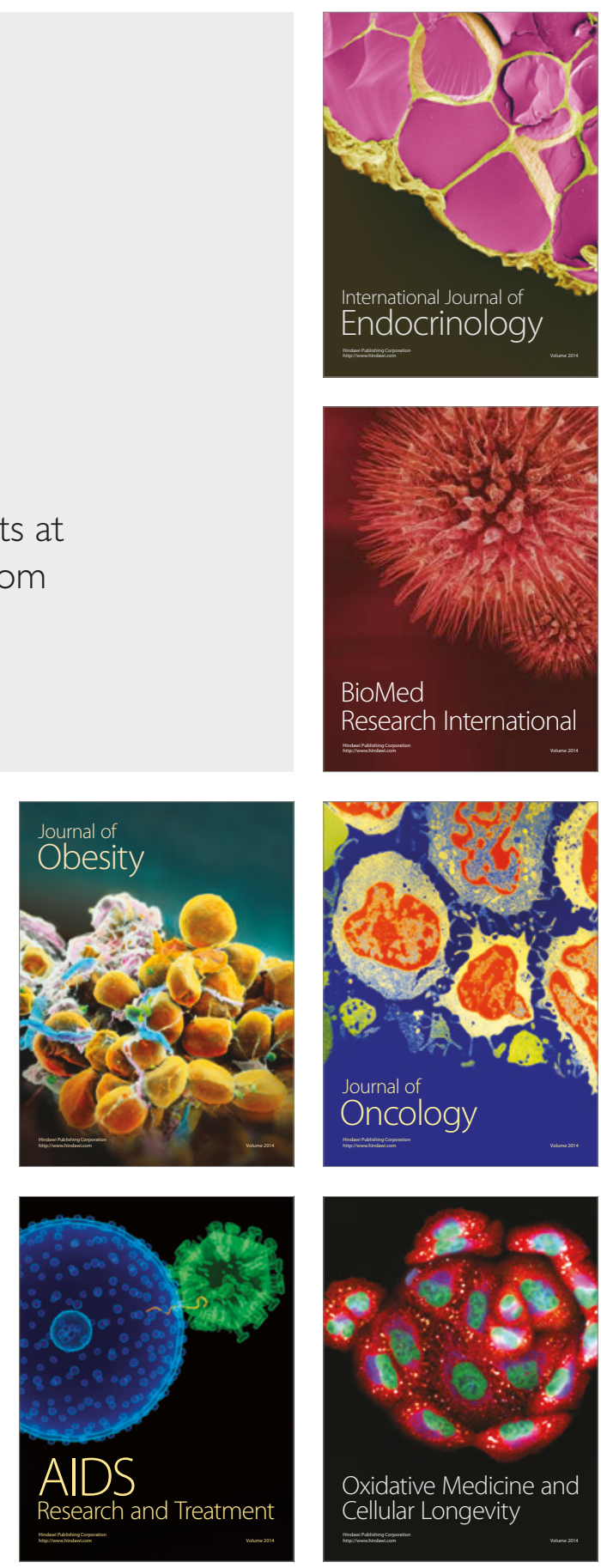